\title{
Food and Nutrition -Where we are Going?
}

\author{
Joshi VK* \\ Associate Editor (Novel Techniques in Nutrition \& Food Science), India
}

*Corresponding author: Joshi VK, Associate Editor (Novel Techniques in Nutrition \& Food Science), Editor- in- chief IJFFT, Consultant CSIR, Member FSSAI, Prof and Head(Rtd), FST, UHF, Nauni, Solan (HP), India

Submission: February 25, 2017; Published: March 22, 2018

\section{Editorial}

Food is the basic necessity of man and for that purpose for all the biological systems. In essence, everything revolves around food. The history is witness that man has used the food as a weapon. On one hand, we advocate the world without starvation and on the other hand create conditions to hinder the free flow of food throughout the world, make standards and regulations that are unachievable and make the food unavailable to the poor masses by fixing exorbitantly higher price. So the mankind has to think if it has to use or not the food as a weapon. On the similar lines, providing healthful and nutritious food is the onus on the mankind as a whole.

The man learnt the art of cooking the food and ultimately arrived at the present level where the food processing and preservation have become an integral part of man. Rather it is a well established industry now and processed foods have become the necessity of mankind. While new methods to develop the food and process them are welcome, we need to be cautious.Whatever methods are invented we need to be assured their safety for consumption for man. A typical example is the use of monosodium glutamate used to give umami flavour, now is considered as harmful. Similarly, with a lot of efforts, made synthetic colours for addition to the food to make them attractive, are now being proven of as a carcinogen. Thanks to the research that have developed bio colours to replace the synthetic colours, which do not have any side effects. unlike the synthetic colours At the same time, we have to develop the methods for their scale up production in proportion to the quantity of food processed. Coupled with it, we need to determine their safety for use by man.

While our food has become safe from the pathogenic microorganisms or toxins, thanks to the research conducted and applied on these aspects, those less pathogenic or the microbes of public health significance can still play havoc with the health of the consumers. It is especially true with respect to the fast foods and the minimal processed foods as revealed by the recently happened incidences. Similarly consumption of food rich in nutrients such as fats or carbohydrates have resulted in obesity or diet related diseases like diabetes, high blood pressure or cardiovascular diseases. Therefore to combat the diseases, a modified approach need to made. The purpose should be to develop foods so as to prevent the incidences of such diseases. On the same plea, the food scientists can develop specific foods for the children, lactating women and aging population. It is a good area of research in the future. Of course, the issue of safety would always be there.

Another example is of genetically modified foods which are being made as the biotechnology is progressed. It has resulted in the application of biotechnology in the crop production eliminating the pathogens and helped developed new varieties with higher yield and with, suitable characteristics. When such knowledge was applied to the production of rennet it was a big milestone. However, when it was applied to the foods to make genetically modified foods many eyebrows were raised especially in the context of allergies and effect on the genes after long time of consumption. Such foods could also affect the basic metabolism after their consumption. So, safety of such foods for man and even animals should be ascertained without any doubt before recommending it for consumption. Though it is also an established fact that there is nothing that should be called as absolutely safe. It is always comparative with respect to the present knowledge and circumstances. Research papers or reviews on these or similar aspects are the need of the hour.

The ancient man made use of fermentation and drying to preserve their excess produce. The use of fermentation achieved excellence and provided the man with foods having both variety of taste and flavour, and nutrition. Extensive research on probiotics have led to establish the potential of such foods for the health of man. How probiotic establish, influence the gut micro-flora of the host is interesting. To know how it effect the metabolism or even the genes of the host, would be of immense value. The indigenously made foods (both unfermented and fermented) have proved to be nutritious and therapeutic. Though the modern man has forgotten this aspects, the mankind is now realizing the potential of such foods. Every day we hear that the consumption of wine can prevent teeth decay or cardiovascular diseases and such reports pour in the literature every day. Then, the question arises if these are based on the scientific investigation or simply based on the survey. Such claims should come only after carefully planned experiments and such research should be welcome. 
There are several instances in the ancient literature where specific foods were provided for the specific ailments. Then with the growth of various faculties of science, this aspects was forgotten and its place has been over taken by the synthetic specific drugs. No doubt it has resulted in the elimination of many diseases, but the food as the 'cure of the disease was eliminated. Now, again the mankind is realizing the potential of certain foods being immunogenic. With the modern sophisticated tools in the hand of a food scientist and the sound knowledge of chemistry, biochemistry, microbiology and food science and technology, coupled with medicine and pharmacology, more elaboration in this direction would not be difficult.

In the present world of energy crisis, the search for alternative source of energy is genuine and bio-fuel emerges out as the convenient fuel. But how much it is justified that the food crops are being advocated for production of ethanol as a bio-fuel, as these crops could be very conveniently used to feed the hungry mouths. It is more painful when we have lot of waste especially from the food industry going down the drain. Not only the waste could be utilized for the production of bio-ethanol, but could be converted into value added products. Such products can be used for the production nutraceuticals which are known to play a lead role in the health of human beings at large. Such type of research needs to be encouraged.

There is large number of health related products being pumped in the market some of which even have not been analyzed even for the active ingredients or the effect has not been demonstrated in suitable animals studies. In all such cases, there should be thorough research and the effects should be validated at more than one place .The journal would encourage this type of approach in the research.

With the advent of science and technology, new methods of analysis and instruments have been invented. Now, it is possible to measures the quantities up to the level a picogram. While these are welcome, there is a need to develop a rationale behind these analysis. Just detection of a substance does not make any sense, but what is needed is to determine its significance. in terms of metabolic level of its toxicity,consumption level and finally, excretion. Similarly, including certain standards or limits for the food product which are not achievable in a normal analytical level is meaningless as it will not be implemented at the ground level. It is of paramount significance as the basic purpose of research is to serve the society and the mankind at large.

Another aspect related to food science and nutrition is adulteration. No doubt many methods have been developed to check the same but it remained unchecked at least in some parts of the world. This is the particularly true in the developing countries. In the past, the man would eat a milk product like burfi without hesitation but now there are every chances of either milk used being adulterated or the khoa (Concentrated milk) used adulterated and those indulge in such practices need to be severely punished by law and society. Our ancestors were lucky in the sense that at least that they eat pure food, drank pure wate and had time to think and see the nature. While emphasis on the development of new methods and techniques should continue, the science should endeavor to awake the society that the food being the basic necessity, must remain to be the purest.
Creative Commons Attribution 4.0 International License

For possible submissions Click Here

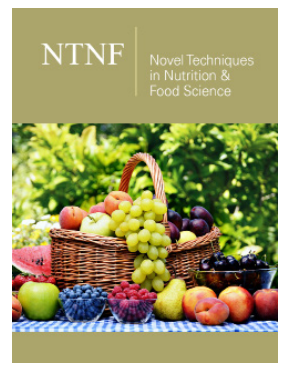

Novel Techniques in Nutrition and Food Science

Benefits of Publishing with us

- High-level peer review and editorial services

- Freely accessible online immediately upon publication

- Authors retain the copyright to their work

- Licensing it under a Creative Commons license

- Visibility through different online platforms 